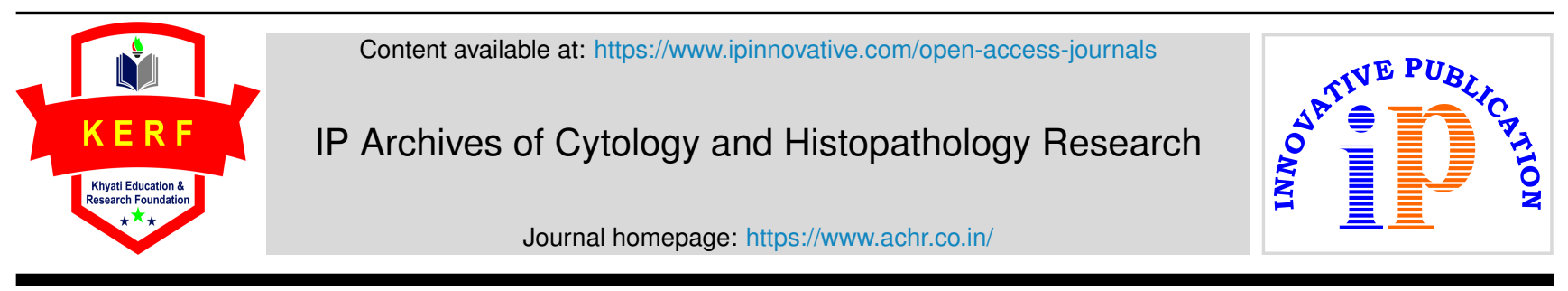

\title{
Editorial
}

\section{Guest in Meckel's diverticulum: An incidentiloma}

\author{
Dhiraj B. Nikumbh ${ }^{1}$,* \\ ${ }^{1}$ Dept. of Pathology, SBH, Government Medical College, Dhule, Maharashtra, India
}

\section{A R T I C L E I N F O}

Article history:

Received 20-11-2021

Accepted 29-11-2021

Available online 02-12-2021
This is an Open Access (OA) journal, and articles are distributed under the terms of the Creative Commons Attribution-NonCommercial-ShareAlike 4.0 License, which allows others to remix, tweak, and build upon the work non-commercially, as long as appropriate credit is given and the new creations are licensed under the identical terms.

For reprints contact: reprint@ipinnovative.com

\section{Dear Researchers,}

'Incidentiloma' word means an abnormal lesion or tumor detected by chance during the medical imaging test during routine examination or during physical examination or during surgery. Meckel's divertivulum (MD) is common congenital anomaly of the gastrointestinal tract, constituting $2 \%$ of population. ${ }^{1}$ It's located on the antimesentric border of ileum and in $90 \%$ cases within $90 \mathrm{cms}$ from the ileocecal valve. ${ }^{2}$ Most of the cases are asymptomatic and in only $4-6 \%$ of its cases showed symptoms. ${ }^{3}$ Symptomatic patient are from the age group less than two years. The most common symptom is hemorrhage constituting 25 to $50 \%$ of complicated patients. ${ }^{1}$ Intestinal obstruction follows bleeding as second complication in $25 \%$ symptomatic patients. ${ }^{3,4}$ The main etiology of the obstruction is from intussception or volvulus around mesodiverticular band. A long Meckel's with narrow base predisposes to intraluminal obstruction causing inflammation, necrosis and perforation. ${ }^{1,4}$ The $3^{r d}$ common symptom is due to diverticulitis in $20 \%$ of symptomatic patients. Rarely it undergoes torsion from twisting of the diverticulum around its narrow base resulting vascular insufficiency and lead to gangrenous changes. ${ }^{1,3}$

In the developing countries like India, intestinal obstruction by ascaris infestation is commonly seen. In most of the cases, it remains asymptomatic. In few cases it results

\footnotetext{
* Corresponding author.

E-mail address: drdhirajnikumbh@gmail.com (D. B. Nikumbh).
}

in complication like obstruction, perforation or gangrene. ${ }^{5}$

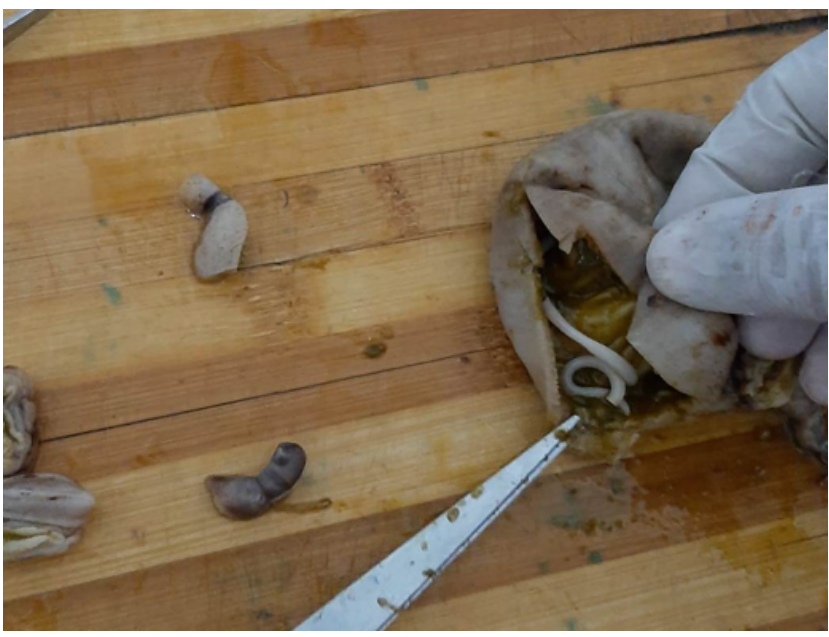

Fig. 1: (Gangrenous Meckel's diverticulum with round worms inside the lumina)

We encountered the case of 2-yrs-old boy presented with abdominal colicky pain. On abdominal examination, rebound tenderness with generalized tenderness in lower abdomen was noted. Patient was febrile and appeared toxic. Plain X-ray abdomen showed multiple air fluid levels with no free gas under the diaphragm. Ultrasonography of abdomen showed dilated small bowel loops and free fluid with internal echos. The patient was posted for 


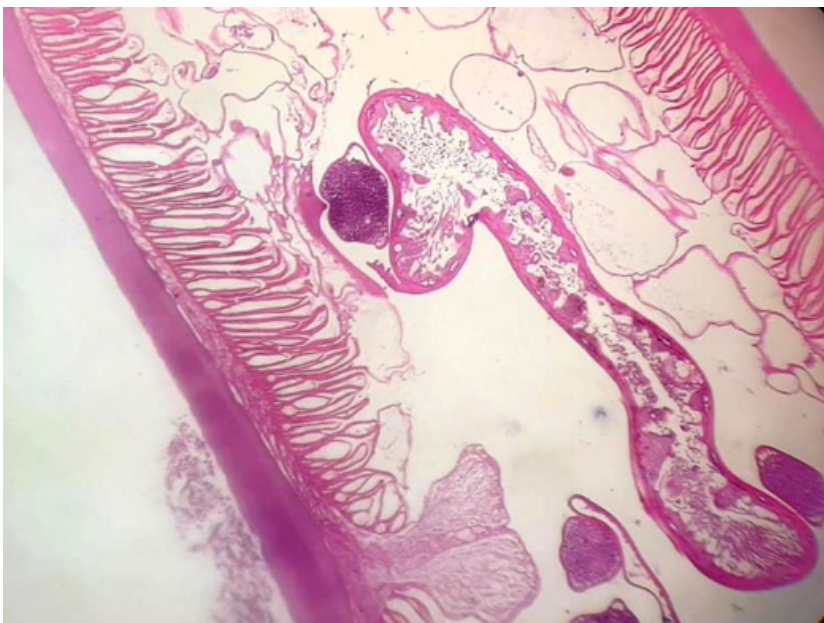

Fig. 2: (Photomicrograph ofA.lumbricoides showing cuticle, lateral cords and myocytes in the lumen of gangrenous Meckel's diverticulum)

emergency exploratory laparotomy. Intraoperative findings revealed Meckel's diverticulum with gangrenous changes involving terminal ileum. Resection of gangrenous segment, diverticulectomy and proximal ileostomy was performed and specimen sent for histopathology. The post operative period was uneventful and child was discharged on $7^{\text {th }}$ day.

To our surprise, on grossing the resected diverticulectomy specimen-the lumina showed multiple round worms of varying length ranging from 9 to12 $\mathrm{cms}$, obstructing the lumina (Figure 1) and leading to vascular insufficiency and gangrene of the wall. The whole of the lining of the Meckel's showed grey brown gangrenous changes. As the interest in histopathology the grossing of the worm was done and sections were taken. Histopathologically cross section confirmed the Ascaris lumbricoides constituting the parts like cuticle, lateral cords and myocytes and some gut parts in the lumina of the Meckel's (Figure 2). The Meckel's showed full thickness hemorrhagic necrosis and chronic inflammatory exudates.

Ascaris lumbricoides causes variety of surgical complications in children due to its wandering nature from its habitat of small intestine ranges from obstruction, organ inflammations, abscess and diverticulitis, appendicitis. ${ }^{1,5}$ Incidence and severity of complications were depends on worms size and the load of worms. Most of the cases were rarely diagnosed preoperatively as Meckel's diverticulum with worm infestation. This is the reason for its incidental finding. ${ }^{5}$

The aim of this editorial to highlight the complications of ascariasis as intestinal obstruction in Meckel's diverticulum. The operating surgeon should be vigilant while handling such cases of gangrenous bowel, keeping the possibility of worm infestation. Early intervention will be helpful in decreasing mortality/morbidity and may salvage the bowel in pediatric patients.

\section{Conflict of Interest}

None.

\section{References}

1. Akhtar T, Alladi A, Siddappa OS, Bahubali G. Gangrenous Meckel's diverticulum secondary to ascariasis in a child. Trop Parasitol. 2012;2(1):1-73.

2. Rossi P, Gourtsoyiannis N, Bezzi M, Ratopoulos V, Capanna G. Meckel's diverticulum imaging diagnosis. Am J Roentgenol. 1996;166(3):567-73. do1:10.2214/ajr.166.3.8623629

3. Cullen JJ, Kelly KA, Moir CR, Hodge DO, Zinsmeister AR, Melton LJ, et al. Surgical management of Meckel's diverticulum.An epidemiologic, population based study. Ann Surg. 1994;220(4):564-8. doi:10.109700000658-199410000-00014

4. Arnold JF, Pellicane JV. Meckel's diverticulum:A ten year experience Ann Surg. 1997;63(4):354-5.

5. Bhatia M, Tomar V, Shankar R. Incisental finding of Meckel's diverticulumin a patient with ascaris induced intestinal obstruction. Arch Int Surg. 2016;6(2):130-2.

\section{Author biography}

Dhiraj B. Nikumbh, Associate Professor

Dept. of Pathology

SBH, Government Medical College, Dhule, Maharashtra, India (1) https://orcid.org/0000-0002-7440-9007

Cite this article: Nikumbh DB. Guest in Meckel's diverticulum: An incidentiloma. IP Arch Cytol Histopathology Res 2021;6(4):228-229. 